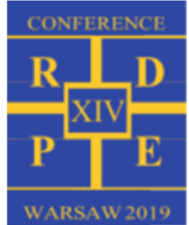

\title{
Pump cavitation in feed water systems - remedies
}

\author{
Krzysztof Karaśkiewicz ${ }^{1, *}$ \\ ${ }^{1}$ W arsaw University of Technology, 00-665 W arsaw, N owowiejska Str. 21/25, krzysztof.karaskiewicz@ itc.pw.edu.pl, Poland
}

\begin{abstract}
The N et Positive Suction Head incipient is a multiple of the N et Positive Suction Head Required in centrifugal pumps. With limited static heads of the feedwater systems, the suction impellers of the feed pumps work in cavitation. The article discusses the ways to deal with the problem of cavitation in such systems.
\end{abstract}

\section{Introduction}

Cavitation in industrial pumps reduces the head, efficiency, leads to excessive vibration and finally cuts the impeller (\$) operating time off due to damage caused by cavitation erosion. This phenomenon is caused by excessive static pressure drop in the pump suction nozzle. Fig. 1 shows the stages of cavitation and their effect on the pump head while maintaining a constant flow.

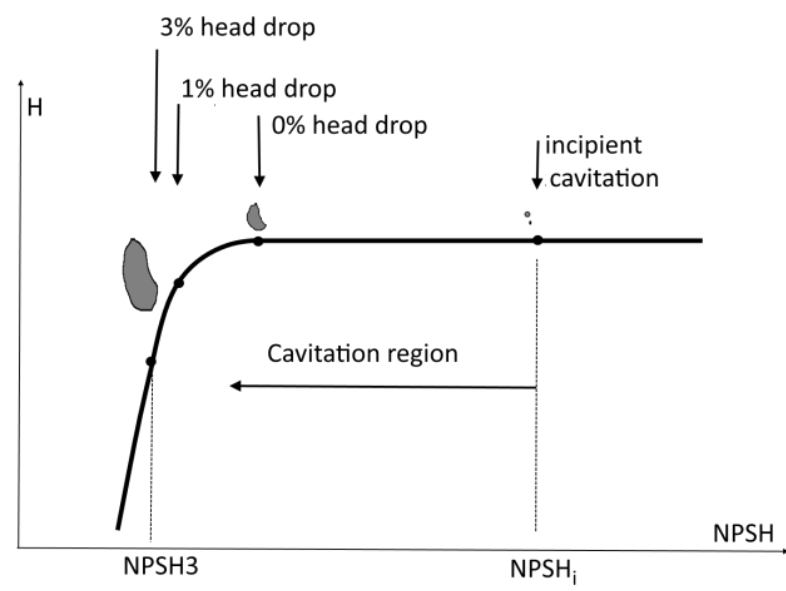

Fig. 1. Stages of cavitation at constant flow rate.

The static pressure before the pump is determined by the characteristics of the suction side of the pumping system determined by the Net Positive Suction Head available.

\section{Net Positive Suction Head Available of a feedwater system}

A diagram of a typical steam generation system in power plants and hot water generation system in an industrial plant is shown in Figure 2.

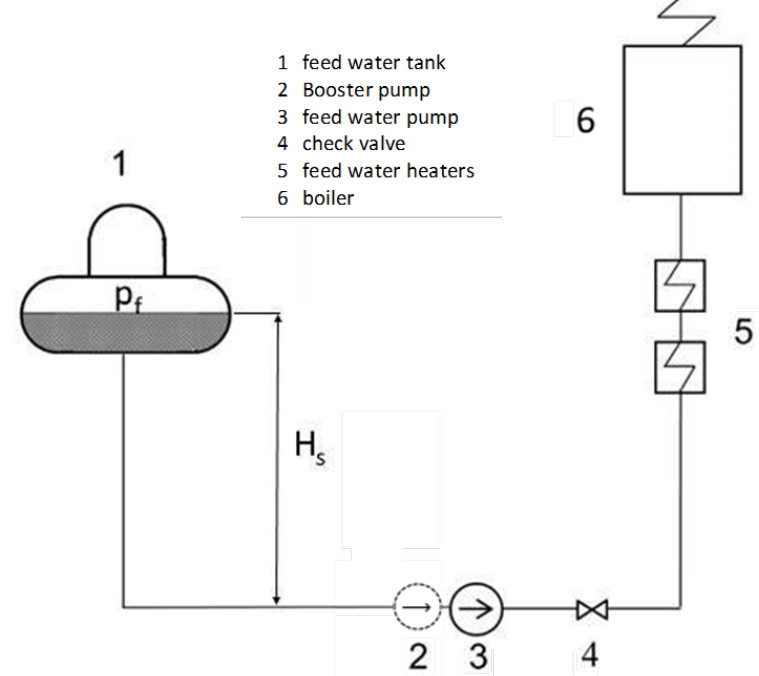

Fig. 2. Feedwater system

The low-pressure side of the system consists of a feedwater tank with a degasser, a suction pipeline with fittings (filter, elbows, etc.), feed water pump with or without a booster pump.

The water in the feed pump is of the temperature above $120^{\circ} \mathrm{C}$. This affects the vapor head, which for such temperatures is $\mathrm{H}_{\mathrm{v}}>22 \mathrm{~m}$.

The disposable excess of the system is determined by the difference between the total amount of energy at the end of the suction system (inlet to the feed pump) and the evaporation height. It can be converted to the form:

$$
N P S H A=\left(H_{f}-H_{v}+H_{s}\right)-H_{s t r}
$$

wherein: $H_{\text {str }} \cong a\left(Q / Q_{n}\right)^{2}$

Taking into account that the pressure in the feed water tank nearly equals vapor pressure $H_{f} \cong H_{v}$

$$
N P S H A \cong H_{s}-a\left(Q / Q_{n}\right)^{2}
$$

Typical static heads in industrial plants are $H_{S}=25 \div 30 \mathrm{~m}$. The losses for optimal flow usually do not 
exceed a few meters, hence the typical values of hydraulic resistance in equation (2) $a=2 \div 3 \mathrm{~m}$.

The NPSHA characteristic limits the pump operation. To avoid cavitation, the $\mathrm{N}$ et Positive Suction $\mathrm{H}$ ead Required must be smaller.

\section{Net Positive Suction Head Required margin}

A commonly used cavitation characteristics in industry is a $3 \%$ drop in head, i.e. NPSHR $=N P S H 3$. $M$ anufacturers provide the NPSH3 characteristic for rated speed. For a suction impeller of a suction specific speed $n_{s s}=230$ (single-suction $i=1$ commercially available pump with a specific speed $n_{q}=20$ ), rated rotational speed $n=50001$ / min, and flow rate $Q_{B E P}=520 \mathrm{~m}^{3} / \mathrm{h}, N P S H 3$ can be expected:

$$
N P S H 3=\left(\frac{n}{n_{S S}}\right)^{4 / 3}\left(\frac{Q_{B E P}}{i}\right)=17 m
$$

This is a relatively large value. Such NPSH can be reduced in three ways:

1. U se of impeller of larger suction specific speed. For the suction specific speed $n_{s s}=280$ and the same rated pump parameters, $N P S H 3 \cong 13 \mathrm{~m}$ can be obtained.

2. Use double suction impeller with the same parameters $n, n_{S S}, Q_{B E P}$. It allows to obtain NPSH3 20\% smaller.

3. Reducing the rotational speed of the pump while increasing the number of stages and impellers diameter to maintain the required head. For example, reducing the speed down to $n=35001 /$ min reduces the N et Positive Suction Head to $N P S H 3 \cong 10 \mathrm{~m}$.

To avoid cavitation some margin is recommended. The NPSH margin is different depending on source literature, for example [1] gives:

$$
\text { NPSH margin }=\left\{\begin{array}{l}
25 \% \\
0,6 m
\end{array}\right. \text { which value is greater }
$$

The Hydraulic Institute [2] recommends:

Table 1. Examples of NPSH margin by HI.

\begin{tabular}{|l|l|l|}
\hline \multicolumn{1}{|c|}{ Industry } & \multicolumn{1}{|c|}{ Application } & \multicolumn{1}{c|}{$\begin{array}{c}\text { NPSH } \\
\text { Margin }\end{array}$} \\
\hline $\begin{array}{l}\text { Petroleum / } \\
\text { hydrocarbon } \\
\text { process }\end{array}$ & $\begin{array}{l}\text { Typical, except vertical } \\
\text { canned pumps }\end{array}$ & $10 \%$ or $1.0 \mathrm{~m}$ \\
\hline Chemical process & Typical & $\begin{array}{l}10 \% \div 20 \% \\
\text { OR } \\
0,6 \mathrm{~m} \div 1,0 \mathrm{~m}\end{array}$ \\
\hline $\begin{array}{l}\text { Electric power } \\
\text { generation }\end{array}$ & $\begin{array}{l}\text { Circulating / cooling } \\
\text { water }\end{array}$ & $1,0 \mathrm{~m}$ \\
\hline $\begin{array}{l}\text { Electric power } \\
\text { generation }\end{array}$ & $\begin{array}{l}\text { Boiler feed }<250 \\
\text { kW/stage }\end{array}$ & $30 \%$ \\
\hline Water & $\begin{array}{l}\text { Typical, stainless steel } \\
\text { or aluminum-bronze } \\
\text { impeller, }<75 \mathrm{~kW} / \text { stage }\end{array}$ & $10 \%$ or 1,5m \\
\hline
\end{tabular}

\begin{tabular}{|l|l|l|}
\hline Building services & $\begin{array}{l}\text { Typical for pumps in } \\
\text { open systems (not } \\
\text { pressurized) }\end{array}$ & $\begin{array}{l}\text { Up to } 10 \% \text { or } \\
0.6 \mathrm{~m}\end{array}$ \\
\hline General & $\begin{array}{l}\text { Often a standard } \\
\text { catalog pump }\end{array}$ & $10 \%$ or $1,0 \mathrm{~m}$ \\
\hline
\end{tabular}

However, they are larger for high energy pumps. M cGuire [3] reports:

Table 2. Examples of NPSH margin according to [3].

\begin{tabular}{|l|l|}
\hline \multicolumn{1}{|c|}{ Application } & \multicolumn{1}{|c|}{$\begin{array}{c}\text { NPSH } \\
\text { Margin }\end{array}$} \\
\hline Water, Cold & $10 \div 35 \%^{(1),(2)}$ \\
\hline Hydrocarbon & $10 \% \%^{(2)}$ \\
\hline $\begin{array}{l}\text { Boiler feed, } \\
\text { small }\end{array}$ & $50 \%{ }^{(3)}$ \\
\hline High energy & $200 \div 300 \%{ }^{(4)}$ \\
\hline \multicolumn{2}{|c|}{ (1) Higher margin for } \\
larger pumps \\
(2) minimum $1 \mathrm{~m}$ \\
(3) up to $1900 \mathrm{~kW}$ at \\
n=3600 rpm \\
(4) $U_{1}$ greater than $30 \mathrm{~m} / \mathrm{s}$ \\
\hline
\end{tabular}

The correct pump operation is defined by NPSHA $\geq$ NPSH3 + NPSH margin but avoiding cavitation imposes a stricter condition NPSHA $\geq \mathrm{NPSH}_{i}$.

\section{Incipient cavitation and NPSHi/NPSH3 ratio}

To determine the safe pump operation area without cavitation, the ratio of NPSH for incipient cavitation and $3 \%$ cavitation is needed.

Figure 3 shows such ratio for pumps with a specific speed from $n_{q}=16$ to $n_{q}=90$.

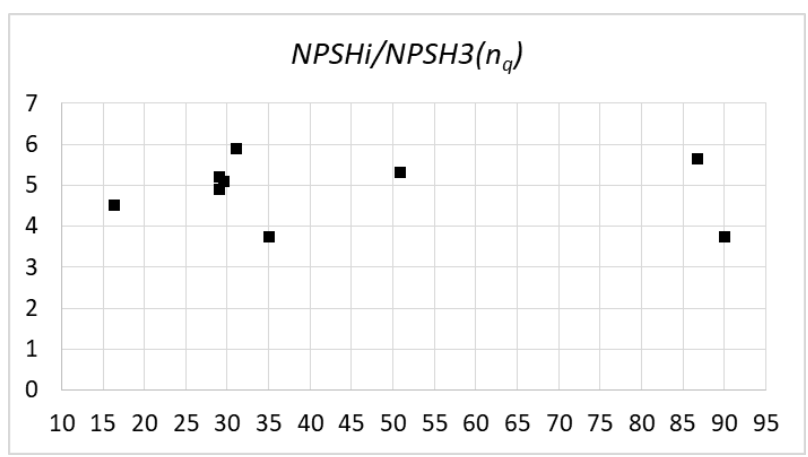

Fig. 3. N PSHi/N PSH 3 ratio for the data from $[4,5,6,7]$ as a function of specific speed.

The ratios range between about 4 and 6 . For very good suction impellers, they are lower and range from 2 to 3 $[1,4]$. Figure 4 shows NPSH ratios for a typical feedwater system with the static head $H_{S}=25 \mathrm{~m}$, a feedwater pump with a double-suction impeller and 25\% margin, and $\mathrm{NPSH}_{i}$ for incipient cavitation. A II is related to $N P S H 3_{B E P}$ $=10 \mathrm{~m}$. $N P S H_{i}$ values as a function of flow rate were estimated based on the studies in $[4,5,6,7]$. 


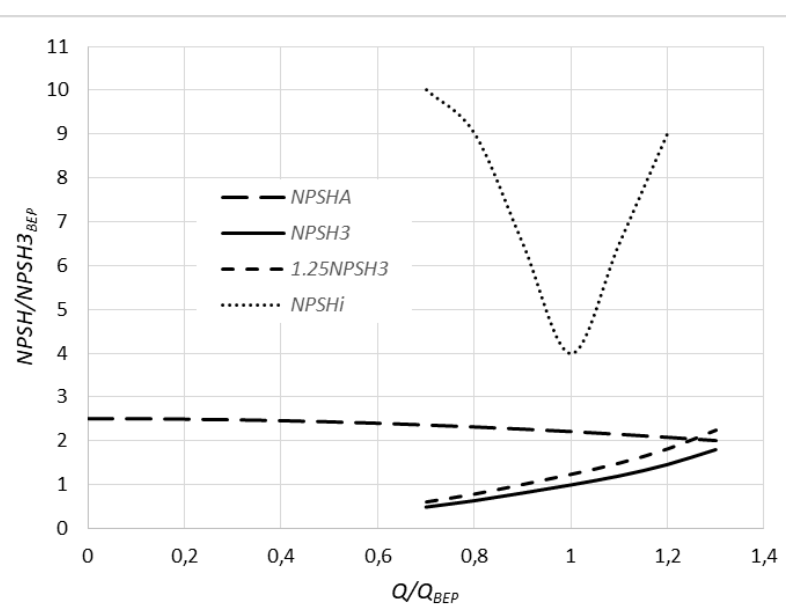

Fig. 4. NPSH curves for feed water pump system in small power plant

The field below the $\mathrm{NPSH}_{i}$ curve is the cavitation area so feedwater pump operates in cavitation because of NPSHA $\leq N P S H_{i}$.

\section{Feedwater system with booster pump}

The use of a low-rotational speed booster pump significantly improves the suction conditions of the feed water pump. The booster pump power is often around $5 \%$ of the feed water pump power. With efficiency of over $80 \%$, additional losses associated with booster pump operation reduce the efficiency of pumping into the boiler by less than a percent. With a booster pump's head of 6 to 8 times the NPSH3 of feed water pump the latter can achieve a wide range of operation without cavitation. The simple structure of the booster pump allows for its long trouble-free operation.

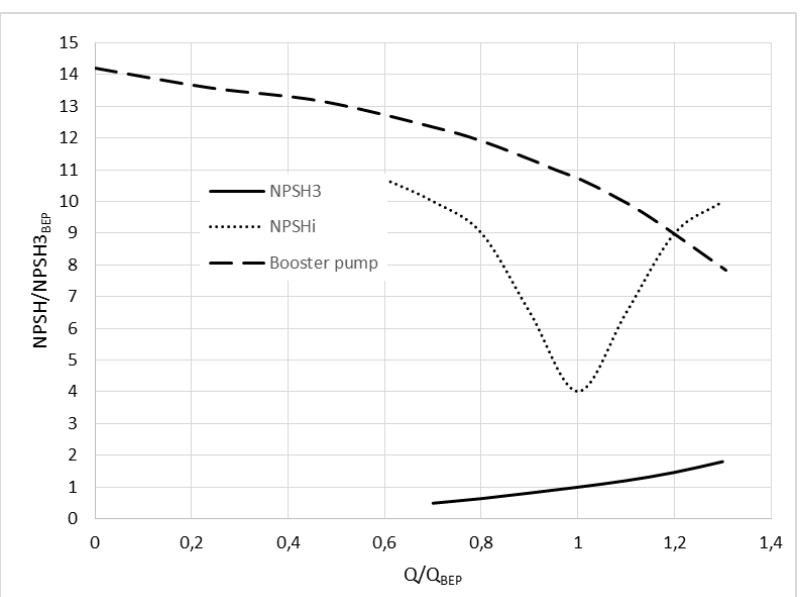

Fig. 5. I mpact of the booster pump on a feed water pump operation

Figure 5 shows NPSH of the system with a booster pump where non-cavitation operation of the feed pump is guaranteed for flow rates $Q<1.2 Q_{B E P}$. The presence of the booster pump slightly increases system complication and decreases efficiency, but extends trouble-free operation time by over 100,000 hours. Despite the tendency to eliminate booster pumps, the final decision should be preceded by LCC analysis.

\section{New materials for suction impeller}

A t existing static heads of the system, without the booster pump the suction impeller of the feed pump operates in cavitation. The conditions for suction impellers material is operation for 40,000 hours. Typical chromium cast steels traditionally used, e.g. GX20Cr14, does not meet this condition but alloys are offered whose cavitation erosion resistance is at least ten times larger. Table 3 contains materials ordered by increasing cavitation resistance according to K SB Lexicon

Table 3. Cavitation erosion: Materials graded by increasing cavitation resistance; weight loss index for typical cast metals (based on grey cast iron JL 1040 with an index of 1.0)

\begin{tabular}{|l|l|l|}
\hline Name & Type & $\begin{array}{l}\text { inde } \\
\text { ks }\end{array}$ \\
\hline Cast steel & GP240GH +QT & 0.8 \\
\hline Tin bronze & CC480K-GS & 0.1 \\
\hline Cast chrome steel & GX20Cr14 & 0.2 \\
\hline $\begin{array}{l}\text { Aluminium multi- } \\
\text { alloy bronze }\end{array}$ & CC333G-GC & 0.1 \\
\hline $\begin{array}{l}\text { Cast chrome nickel } \\
\text { steel }\end{array}$ & GX5CrNi19-10 & 0.05 \\
\hline Noridur & $\begin{array}{l}\text { GX3CrNiM oCuN24- } \\
6-2-3\end{array}$ & 0.02 \\
\hline
\end{tabular}

Leading producers offer cast steels with increased resistance to cavitation erosion e.g. Noridur and Noriclor (K SB ) or X-Cavalloy (Flowserve). They are compared in table 4.

Table 4. Commercial cast steels resistant to cavitation erosion.

\begin{tabular}{|l|l|l|l|}
\hline & Noridur & Noriclor & X-Cavalloy \\
\hline $\mathrm{C}$ & 0.04 & 0.04 & 0,1 \\
\hline $\mathrm{Si}$ & 1.5 & 1.0 & 0,5 \\
\hline $\mathrm{M} \mathrm{n}$ & 1.5 & 1.0 & 15,5 \\
\hline $\mathrm{Cr}$ & $23.0-26.0$ & $22.0-25.0$ & 18 \\
\hline $\mathrm{Ni}$ & $5.0-8.0$ & $4.5-6.5$ & 0,5 \\
\hline $\mathrm{M} \mathrm{o}$ & $2.0-3.0$ & $4.5-6.0$ & - \\
\hline $\mathrm{Cu}$ & $2.75-3.5$ & $1.5-2.5$ & - \\
\hline $\mathrm{N}$ & $0.10-0.2$ & $0.15-0.25$ & 0,25 \\
\hline
\end{tabular}

Noridur and Noriclor are based on chrome, nickle and molybdenum whereas $X$-Cavalloy distinguishes by a large share of $15.5 \% \mathrm{M}$ anganese.

\section{Conclusion}

The feed pumps operation in power plant systems takes place at static heads of $25 \div 30 \mathrm{~m}$ resulting from typical el evation heights of the feed water tank.

Even for suction impellers with large suction specific speed and relatively large NPSH margin it leads to cavitation operation. One way is to avoid cavitation by 
using a booster pump. The reliability of single-stage, double-suction pumps working usually as booster pumps is very high due to the lack of balancing system, low rotational speed, and simple structure. The disadvantage of the system with a booster pump is slightly lower efficiency reaching a fraction of a percent. Therefore, the assessment of the system operation with or without a booster pump should be preceded by LCC analysis.

Without a booster pump, an acceptable impeller lifetime of 40,000 hours requires materials with high resistance to cavitation erosion. New cast steels with erosion resistance more than ten times higher than typical chromium cast steels are the answer to these needs. However, further material advancement extending impeller lifetime is required.

\section{References}

1. Gulich J.F. - Centrifugal Pump - SpringerVerlag, B erlin Heidel berg, (2008)

2. ANSI/HI 9.6.1-2012 Rotodynamic Pumps Guideline for N PSH M argin

3. M cGuire, J. T., So Y ou N eed Pumps for a Revamp!, Pumps \& Systems Magazine, A ugust (1996).

4. Schiavello B., Visser F.C. - Pump cavitation various NPSH R criteria, NPSH margins, and impeller life expectancy - Proceedings of the twenty-fifth 138 International Pump Users Symposium, (2009)

5. M d Rakibuzzaman, Sang-Ho Suh, Hyoung-Ho $\mathrm{K}$ im, $\mathrm{Y}$ oung-Hoon J - Relationship between Cavitation Incipient and N PSH Characteristic for Inverter Drive Centrifugal Pumps - The KSFM Journal of Fluid Machinery - V ol. 18, No. 6, pp.76-80, (2015)

6. Sedlar M ., Sputa O., K omarek M - CFD A nalysis of Cavitation Phenomena in M ixedFlow Pump, International Journal of Fluid Machinery and Systems, V ol. 5, N o. 1, January$M$ arch (2012)

7. Sedlár M., Komárek M., Vyroubal M., Doubrava V., V archola M., HIbocan P. Experimental and numerical analysis of unsteady behaviour of high efficiency mixedflow pump - , EPJ Web of Conferences 67, 02104 (2014)

8. KSB Lexicon https://www.ksb.com/centrifugal-pumplexicon/cavitation-erosion/328182/

9. M cCaul C. - A cavitation-resistant casting alloy for pumps - status after ten years' commercial use - in Advanced Materials for Fluid Machinery, Wiley, (2004) 